\title{
Effects of repeated exposures to marine cyanobacterial secondary metabolites on feeding by juvenile rabbitfish and parrotfish
}

\author{
Robert W. Thacker*, Dale G. Nagle**, Valerie J. Paul \\ University of Guam Marine Laboratory, UOG Station, Mangilao, Guam 96923, USA
}

\begin{abstract}
Secondary metabolites isolated from marine algae and cyanobacteria can act as feeding deterrents to a variety of herbivores, but past studies have rarely considered the responses of herbivores to these compounds over time. We examined the influence of repeated preference tests on the responses of juvenile rabbitfish Siganus spinus and juvenile parrotfish Scarus schlegeli to malyngamide A, malyngamide B, and malyngolide, 3 secondary metabolites from the marine cyanobacterium. Lyngbya majuscula. We offered fish choices between control food and food treated singly with these compounds in series of 3 to 5 preference tests, during which fish were either fed only during tests (periodic feeding) or continuously fed. Each of the 3 compounds deterred feeding by juvenile rabbitfish and parrotfish, but the magnitude of deterrence varied over time and between the 2 feeding protocols. In the continuous feeding protocol, rabbitfish were more discriminating in later trials with malyngamides $A$ and $B$, while parrotfısh were more discrimunating in later trials with malyngamide $A$. Levels of deterrence of malyngamides $A$ and $B$ did not change over time in the periodic feeding protocols, and were lower than in the continuous feeding protocols for both species. Malyngolide generated the same amount of feeding deterrence in each feeding protocol and the fishes showed no changes in their consumption of malyngolide over time. Changes in hunger level and the amount of experience with foods may influence whether fish learn to reject foods that contain feeding deterrents, though the extent of this learning varies among compounds and fish species. These behavioral mechanisms may lead to the consumption of broader diets when preferred foods are less abundant.
\end{abstract}

KEY WORDS: Chemical defense $\cdot$ Natural products $\cdot$ Learning Cyanobacteria Lyngbya Siganidae Scaridae

\section{INTRODUCTION}

The effectiveness of prey chemical defenses against a predator can depend on the recent experiences of the predator (e.g. Lee \& Bernays 1988, Provenza \& Cincotta 1993, Cronin \& Hay 1996). Consumers may learn to accept foods that are initially unpalatable (Provenza \& Cincotta 1993) or learn to reject foods that are initially palatable (Lee \& Bernays 1988, Provenza et al.

Present addresses:

- Kewalo Marine Laboratory, 41 Ahui St., Honolulu, Hawai 96813, USA.E-mail: rthacker@hawaii.edu

- Department of Biochemistry, University of Texas, Southwestern Medical Center at Dallas, 5323 Harry Hines Blvd, Dallas, Texas 75235, USA
1990, Gerhart 1991), depending on the post-ingestive consequences of those foods. After experience with a food containing toxins or other feeding deterrents, many herbivores will learn to avoid that food (Rozin 1976, Lee \& Bernays 1990, Provenza \& Cincotta 1993). Hunger stress may alter the formation of learned aversions, with higher levels of hunger resulting in a greater acceptance of chemically defended food types (Cronin \& Hay 1996). This behavior can lead to a consumer accepting lower quality (more chemically defended) food types as the abundance of higher quality (less chemically defended) food types in the environment decreases (Dill 1983).

Juvenile rabbitfish Siganus spinus and $S$. argenteus are very abundant on Guam reefs during annual 
recruitment events that occur in May and June (Kami \& Ikehara 1976). In some years, extremely large numbers of rabbitfish recruits consume almost all of the seaweeds and seagrasses on reef flats around Guam (Tsuda \& Bryan 1973, authors' pers. obs.). The presence of large schools of rabbitfish consuming depletable algal resources fits an 'expanding specialist' model of diet selection (Mitchell 1990). When a large number of foragers are consuming depletable resources, all individuals should first specialize on the richest resource and include lower quality resources only as richer resources become depleted. Rabbitfish indeed appear to rapidly consume the most palatable algae on the reef flats and gradually begin to accept less palatable algae as the relative abundances of less palatable algae increase. However, rabbitfish will not eat some algal species, even if they are starving. This behavior can lead to large fish kills during recruitment pulses (Tsuda \& Bryan 1973, authors' pers. obs.). Earlier studies of $S$. spinus and $S$. argenteus food preferences found that rabbitfish were not deterred by crude extracts or isolated metabolites from a variety of macroalgae, but were deterred by crude extracts of the benthic marine cyanobacterium Lyngbya majuscula (Paul et al. 1993). In repeated experiments with $S$. argenteus, changes in the palatability of crude extracts from 5 species of macroalgae were interpreted as variation in either fish hunger or algal secondary metabolite content between trials (Paul et al. 1990).

Lyngbya majuscula produces a variety of secondary metabolites, including malyngamides $A$ and $B$ and malyngolide (Moore 1981) (Fig. 1). Malyngamides A and $\mathrm{B}$ can act as feeding deterrents to herbivorous fishes and invertebrates (Paul \& Pennings 1991, Pennings \& Paul 1993). However, laboratory assays used to examine the effects of secondary metabolites on feeding have generally used a single test of a compound on a group of fish that may have experienced several compounds in multiple assays (e.g. Paul et al. 1993, Hay et al. 1994, Lumbang \& Paul 1996). Although questions about fish sensitization or habituation to secondary metabolites have been raised (Lumbang \& Paul 1996), few studies have explicitly tested how fish respond to secondary metabolites after repeated feeding assays. Juvenile parrotfish Scarus schlegeli are our most common vertebrate subjects in laboratory tests of feeding deterrence. Repeated exposures to secondary metabolites could generate variability in our standard assays with these herbivores.

In this study, we sought to examine the responses of juvenile rabbitfish Siganus spinus and juvenile parrotfish Scarus schlegeli to repeated preference tests with 3 secondary metabolites found in Lyngbya majuscula: malyngamide $A$, malyngamide $B$, and malyngolide. We hypothesized that each compound would deter fish<smiles>CCCCCCC[C@H](CC/C=C/CCC(=O)N(C)C/C(=C/Cl)C/C(=C\C(=O)N1CC(OC)=CC1=O)OC)OC</smiles>

Malyngamide A<smiles>CCCCCCC[C@H](C)OC</smiles>

Malyngamide B

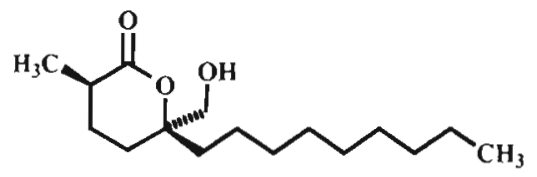

Malyngolide

Fig. 1. Chemical structures of malyngamide A, malyngamide $B$, and malyngolide from the benthic marine cyanobacterium Lyngbya majuscula

feeding and that fish would learn to avoid these compounds over time. In addition, we either fed fish only when conducting preference tests or continuously fed fish. We hypothesized that fish fed continuously would be more deterred by secondary metabolites than fish fed at regular intervals.

\section{METHODS}

Study organisms. Juvenile Siganus spinus (total length 3 to $5 \mathrm{~cm}$ ) and Scarus schlegeli (total length 8 to $12 \mathrm{~cm}$ ) were collected by net from shallow reef flats around Guam. Twenty $S$. spinus were held individually, throughout the study, in 2 l tanks equipped with flow-through seawater. Thirteen $S$. schlegeli were held individually in $20 \mathrm{l}$ tanks, also equipped with flowthrough seawater. Fish were fed daily when not involved in an experiment, on an artificial maintenance diet containing $200 \mathrm{ml}$ of water, $10 \mathrm{~g}$ of agar, $13 \mathrm{~g}$ of ground commercial catfish pellets, and $5 \mathrm{~g}$ of freeze-dried and ground Enteromorpha clathrata (Roth), a palatable green alga.

Isolation of secondary metabolites. Malyngolide: Lyngbya majuscula (voucher specimens at the University of Guam Marine Laboratory and Oregon State University College of Pharmacy) was collected from 
Rizal Beach, Guam on 12 March 1995. 489 g (dry weight) of material was stored at $-20^{\circ} \mathrm{C}$ until exhaustively extracted (4 times) with a 1:1 mixture of dichloromethane:methanol (v:v). The crude extract (15.95 g oil) was subjected to silica gel vacuum chromatography using a gradient of hexanes to ethyl acetate to ethanol. The least polar fractions [eluting from 0 to $25 \%$ ethyl acetate:hexanes (v:v)] were combined and further chromatographed using a $60 \mathrm{cc}(10 \mathrm{~g})$ Mega Bond Elut ${ }^{\mathbb{B}}$ silica column and a gradient of dichloromethane to methanol. The fractions eluting from 0 to $5 \%$ methanol:dichloromethane were then separated by reversed-phase chromatography (Mega Bond Elut ${ }^{(0)}$ $\mathrm{C}_{18}$ column, $10 \%$ water:methanol (v:v) to $100 \%$ methanol). Fractions eluting with $10 \%$ water:methanol were further separated by HPLC (Econosil ${ }^{\circledR}$ silica $10 \mu \mathrm{m}, 250 \times 22 \mathrm{~mm}$ column, $65 \%$ ethyl acetate:hexanes (v:v), refractive index detection) and decolorized with activated charcoal ( $2.5 \mathrm{~g}$ in diethyl ether) to yield $1.65 \mathrm{~g}$ of malyngolide, which was only part of the total malyngolide in the crude extract. The structure of malyngolide was confirmed by ${ }^{1} \mathrm{H}$ and ${ }^{13} \mathrm{C}$-NMR spectroscopy.

Malyngamides: Malyngamides $\mathrm{A}$ and $\mathrm{B}$ were isolated from an acetone extract of the sea hare Stylocheilus longicauda, which sequesters these compounds from Lyngbya (Paul \& Pennings 1991). Silica gel vacuum chromatography separation of $7.33 \mathrm{~g}$ of extract with a gradient of hexanes to ethyl acetate to methanol produced a $5.2 \mathrm{~g}$ malyngamide-enriched fraction. Small portions of this enriched material were then periodically subjected to HPLC purification [Econosil ${ }^{\otimes}$ Silica $10 \mu \mathrm{m}, 250 \times 22 \mathrm{~mm}$ column, $65 \%$ ethyl acetate:hexanes ( $V: v)$, refractive index detection) to yield pure malyngamides $\mathrm{A}$ and $\mathrm{B}$. The structures of malyngamides $A$ and $B$ were confirmed by ${ }^{1} \mathrm{H}-\mathrm{NMR}$.

Artificial foods. To measure preferences between different foods, fish were presented with artificial foods molded onto fiberglass window screening, using a method similar to that of Hay et al. (1994) and Lumbang \& Paul (1996). The artificial foods consisted of $36 \mathrm{ml}$ of water, $0.72 \mathrm{~g}$ of agar, and $4 \mathrm{~g}$ of powdered freeze-dried Enteromorpha clathrata. Pure compounds were added to the artificial food as a percentage of dry mass (malyngamide A: $1 \%$ for rabbitfish, $0.5 \%$ for parrotfish; malyngamide B: $0.5 \%$; malyngolide: $0.4 \%$ ) that reflected natural concentrations in Lyngbya majuscula (Pennings et al. 1996). To incorporate these compounds into the artificial foods, an appropriate amount of compound was dissolved in either diethyl ether or dichloromethane and added to the powdered Enteromorpha. Solvent alone was added to control foods. Solvent was removed from the Enteromorpha by rotary evaporation. Foods were then prepared by boiling the agar and water in a microwave, adding the Enteromor- pha, mixing the diet, then pouring the diet into a mold backed with fiberglass window screening. The mold had 2 parallel $2.6 \times 25 \mathrm{~cm}$ openings cut in it with a depth of $2 \mathrm{~mm}$. One opening of the mold was filled with control food and the other with treated food containing Lyngbya compounds. As the agar cooled, the food assumed the shape of the mold and became attached to the screening. The molds were removed and the screening was cut so that a length of screening contained both control and treated foods. For rabbitfish, food strips were $1 \mathrm{~cm}$ wide, with $6 \times 15$ square openings in the screen for both control and treated foods. For parrotfish, food strips were $2.5 \mathrm{~cm}$ wide, with $17 \times 15$ square openings in the screen for both control and treated foods.

Learning assays. To determine if fish learned to accept or reject these secondary metabolites, we conducted preference tests over time. Fish were presented with control and treated foods twice daily or once daily, repeated for 3 to $5 \mathrm{~d}$ (Table 1). Food strips were monitored periodically and removed when a fish had eaten 50 to $75 \%$ of one of the foods. Consumption was measured by counting the number of squares of screening from which control or treated food was removed. If a fish did not feed during a preference test, it was excluded from all analyses

We followed 2 protocols when testing feeding preferences, a periodic feeding protocol and a continuous feeding protocol. Fishes were initially tested either once or twice each day, with no additional food, making these tests similar to previous studies performed in our laboratory (Paul et al. 1993, Lumbang \& Paul 1996). We observed that fishes appeared hungry between preference tests, often 'spitting' water at passers-by. Fishes would immediately begin eating when food strips were placed in their tanks and would even eat from food strips while the strips were still in an observer's hand. We designed a second protocol to give fishes continuous exposure to foods, allowing the fishes to be more satiated. The same individuals were tested with each protocol. There was some variation in the details of each protocol, dependent upon the amount of compound available (Table 1). In general, for periodic feeding protocols, fish were fed only when their food preferences were tested, either once or twice per day. For continuous feeding protocols, fish were either fed strips of control food between preference tests or allowed continuous access to control and treated foods. In the latter case, each day's consumption of food was totaled (all the food eaten in a given day from control and treated strips). Rabbitfish experiments were conducted in the following order: (1) malyngamide $A$, periodic; (2) malyngamide A, continuous; (3) malyngolide, continuous; (4) malyngamide $B$, continuous; (5) malyngolide, periodic; (6) malynga- 
Table 1 Compounds, their concentrations, and the feeding protocols followed in experiments with juvenile rabbitfish Siganus spinus and parrotfish Scarus schlegeli. The number of assays, the number of days over which assays were conducted, and the number of fish feeding in the assays are also listed

\begin{tabular}{|c|c|c|c|c|c|}
\hline Compound & Periodic feeding & Continuous feeding & Assays & Days & Fish \\
\hline \multicolumn{6}{|l|}{ Rabbitfish } \\
\hline Malyngamide A $1 \%$ & $\begin{array}{l}\text { Fed only when testing food } \\
\text { preferences, twice each day }\end{array}$ & $\begin{array}{l}\text { Fed additional control food } \\
\text { between preference tests }\end{array}$ & 5 & 2.5 & 9 \\
\hline Malyngamide B $0.5 \%$ & $\begin{array}{l}\text { Fed only when testing food } \\
\text { preferences, once each day }\end{array}$ & $\begin{array}{l}\text { Allowed continuous access to } \\
\text { both control and treated foods }\end{array}$ & 3 & 3 & 9 \\
\hline Malyngolide $0.4 \%$ & $\begin{array}{l}\text { Fed only when testing food } \\
\text { preferences, once each day }\end{array}$ & $\begin{array}{l}\text { Fed additional control food } \\
\text { between preference tests }\end{array}$ & 5 & 5 & 8 \\
\hline \multicolumn{6}{|l|}{ Parrotfish } \\
\hline Malyngamide A $0.5 \%$ & $\begin{array}{l}\text { Fed only when testing food } \\
\text { preferences, once each day }\end{array}$ & $\begin{array}{l}\text { Allowed continuous access to } \\
\text { both control and treated foods }\end{array}$ & 3 & 3 & 13 \\
\hline Malyngamide B $0.5 \%$ & $\begin{array}{l}\text { Fed only when testing food } \\
\text { preferences, once each day }\end{array}$ & $\begin{array}{l}\text { Allowed continuous access to } \\
\text { both control and treated foods }\end{array}$ & 3 & 3 & 10 \\
\hline Malyngolide $0.4 \%$ & $\begin{array}{l}\text { Fed only when testing food } \\
\text { preferences, once each day }\end{array}$ & $\begin{array}{l}\text { Fed additional control food } \\
\text { between preference tests }\end{array}$ & 5 & 5 & 10 \\
\hline
\end{tabular}

mide $B$, periodic. Parrotfish experiments were conducted in the following order: (1) malyngolide, continuous; (2) malyngolide, periodic; (3) malyngamide $B$, continuous; (4) malyngamide $B$, periodic; (5) malyngamide $A$, continuous; (6) malyngamide $A$, periodic.

Fish were given excess amounts of the artificial maintenance diet for at least $3 \mathrm{~d}$ between experiments with different feeding protocols or compounds. Treated foods not consumed during the assays were extracted with dichloromethane and analyzed by thin layer chromatography (TLC) to ensure that the test compounds were still present. No decomposition of metabolites was observed by TLC.

Statistical analyses. Since consumption of the control and treated foods was measured repeatedly over time for individual fish, a repeated measures analysis of variance (ANOVA) with factors for food type (compound: control vs treated) and feeding protocol (protocol: continuous vs periodic) was used to determine the effects of test compound, feeding protocol, and time on food consumption. Blocking these factors by fish allowed the paired nature of control and treated foods and feeding protocols to be examined over time (Winer 1971). All analyses were performed with the SYSTAT software package (Wilkinson et al. 1992). The data met the assumptions of these ANOVAs, as tested by Lilliefors's test for normality and Bartlett's test for homogeneity of variances. Data were first analyzed for the significance of a protocol $\times$ compound $\times$ time interaction (whether the deterrent effect of a compound

Table 2. Siganus spinus. Repeated measures ANOVAs of rabbitfish consumption of foods treated with Lyngbya majuscula compounds. Only factors relevant to our hypotheses are shown

\begin{tabular}{|c|c|c|c|c|c|}
\hline Effect & $\mathrm{df}$ & Effect MS & Error MS & $F$ & $\mathrm{p}$ \\
\hline \multicolumn{6}{|l|}{ (A) Malyngamide A $1 \%$} \\
\hline Compound & 1,8 & 36211 & 678 & 53.4 & $<0.001$ \\
\hline Compound $\times$ Time & 4,32 & 315 & 167 & 1.9 & 0.137 \\
\hline Compound $\times$ Protocol & 1,8 & 661 & 169 & 3.9 & 0.083 \\
\hline Compound $\times$ Time $\times$ Protocol & 4,32 & 874 & 90 & 9.8 & $<0.001$ \\
\hline \multicolumn{6}{|l|}{ (B) Malyngamide B $0.5 \%$} \\
\hline Compound & 1,8 & 233151 & 11182 & 20.9 & 0.002 \\
\hline Compound $\times$ Time & 2,16 & 22984 & 2512 & 9.2 & 0.002 \\
\hline Compound $\times$ Protocol & 1,8 & 101323 & 12847 & 7.9 & 0.023 \\
\hline Compound $\times$ Time $\times$ Protocol & 2,16 & 16180 & 1652 & 9.8 & 0.002 \\
\hline \multicolumn{6}{|l|}{ (C) Malyngolide $0.4 \%$} \\
\hline Compound & 1,7 & 4666 & 306 & 15.2 & 0.006 \\
\hline Compound $\times$ Time & 4,28 & 232 & 262 & 0.9 & 0.486 \\
\hline Compound $\times$ Protocol & 1,7 & 31 & 312 & 0.1 & 0.763 \\
\hline Compound $\times$ Time $\times$ Protocol & 4,28 & 396 & 272 & 1.5 & 0.241 \\
\hline
\end{tabular}


changed over time differently in each protocol). If this interaction term was significant, the 2 feeding protocols were then analyzed separately with post-hoc repeated measures ANOVAs with factors for the effects of compound and time on food consumption. In each case, the compound $x$ time interaction would indicate whether the deterrent effect of the treated food changed over time. Separate analyses of compound and feeding protocol were conducted for each time period to test the significance of compound $x$ protocol interactions (whether the deterrent effect of a food depended upon feeding protocol). Finally, the compound effect determined whether more control food was consumed than treated food. Some effects in these analyses are not relevant to our conclusions, including those of protocol, time, and the protocol $x$ time interaction. Any differences in consumption of foods due to these effects are consequences of the experimental design, as fish were offered different amounts of foods in the different feeding protocols and could consume different total amounts of foods on different days within an experiment.

\section{RESULTS}

\section{Rabbitiish}

Malyngamide A. Juvenile rabbitfish consumption of malyngamide A showed a significant compound $x$ time $\times$ protocol interaction (Table $2 \mathrm{a}$, Fig 2a, b), indicating differences in feeding deterrence over time between the 2 feeding protocols. Separate analyses of each protocol revealed that significantly more control food was consumed than treated food (periodic: $F_{1.8}=58.2$, $\mathrm{p}<0.001$; continuous: $\left.F_{1,8}=38.0, \mathrm{p}<0.001\right)$. Only for the continuous protocol was the compound $x$ time interaction significant $\left(F_{4.32}=7.0, \mathrm{p}<0.001\right)$, indicating that feeding deterrence increased over time. Separate analyses for each time period indicated that in the last meal, significantly more deterrence was found in the continuous protocol than in the periodic protocol (compound $x$ protocol interaction: $F_{1,8}=26.0, \mathrm{p}<0.001$ ). Thus, while malyngamide $\mathrm{A}$ deterred feeding in both protocols, in the continuous protocol, rabbitfish were more deterred after repeated exposures, while the level of deterrence was consistent in the periodic protocol (Fig. 2a, b).

Malyngamide B. Juvenile rabbitfish consumption of malyngamide $B$ also showed a significant compound $x$ time $\times$ protocol interaction (Table 2b, Fig. 2c, d), indicating differences in feeding deterrence over time be-
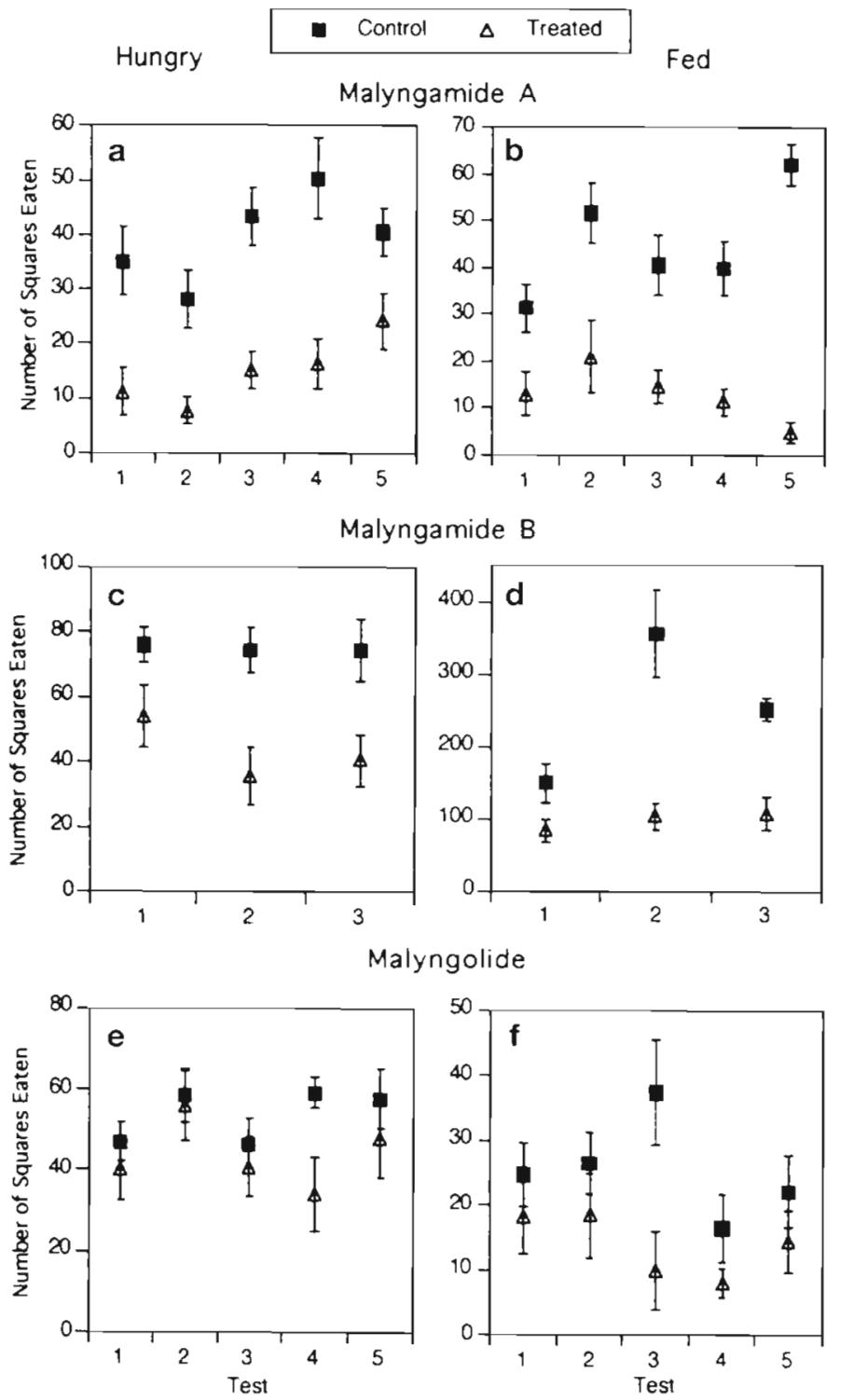

Fig. 2. Siganus spinus. Rabbitfish consumption of control foods and foods treated with malyngamide $A$, malyngamide $B$, or malyngolide in periodic or continuous feeding protocols. Means and standard errors are plotted for each test. Note that the scales of the $y$-axes vary

tween the 2 feeding protocols. Separate analyses indicated that significantly more control food was consumed than treated food in each protocol (periodic: $F_{1,8}=13.6, \mathrm{p}=0.006$; continuous: $F_{\mathrm{l}, 8}=13.9, \mathrm{p}=0.006$ ). Only for the continuous protocol was the compound $x$ time interaction significant $\left(F_{2,16}=10.1, \mathrm{p}=0.001\right)$, indicating that feeding deterrence changed over time. Separate analyses for each time period showed that in Tests 2 and 3 significantly more deterrence was found in the continuous protocol than in the periodic protocol (Test 2 compound $\times$ protocol: $F_{1,8}=11.8, \mathrm{p}=0.009$; 
Test 3 compound $\times$ protocol: $\left.F_{1,8}=7.4, p=0.026\right)$. Although malyngamide $B$ deterred feeding in both protocals, in the continuous protocol, rabbitfish were more deterred after repeated exposures, while the level of deterrence did not change in the periodic protocol (Fig. 2c, d).

Malyngolide. Consumption of malyngolide did not show a significant compound $\times$ time $\times$ protocol interaction (Table 2c, Fig. 2e, f). For both protocols, significantly more control food was consumed than treated food (Table $2 \mathrm{c}$, Fig. 2e, f). Thus, rabbitfish were deterred by malyngolide in each protocol.

\section{Parrotfish}

Malyngamide A. Juvenile parrotfish consumption of malyngamide A showed a significant compound $\times$ time $\times$ protocol interaction (Table 3a, Fig. 3a, b), indicating differences in deterrence over time between the 2 feeding protocols. Separate analyses showed that significantly more control food was consumed than treated food in each protocol (periodic: $F_{1,12}=30.9, \mathrm{p}<$ 0.001 ; continuous: $\left.F_{1.12}=25.3, p<0.001\right)$. Only for the continuous protocol was the compound $x$ time interaction significant $\left(F_{2,24}=5.4, \mathrm{p}=0.012\right)$. Separate analyses for each time period revealed that in the last test, there was a significantly larger amount of feeding deterrence in the continuous protocol than in the periodic protocol (protocol $\times$ compound $F_{1,12}=16.4, \mathrm{p}=$ 0.002 ). Although malyngamide A deterred feeding in both protocols, in the continuous protocol, parrotfish were more deterred after repeated exposures, while the level of deterrence was consistent in the periodic protocol (Fig. 3a, b)
Malyngamide B. Parrotfish consumption of malyngamide $B$ did not show a significant compound $\times$ time $x$ protocol interaction, although a significant compound $\times$ protocol interaction was observed (Table $3 \mathrm{~b}$, Fig $3 c_{1}$ d). Separate analyses for each protocol indicated that significantly more control food was consumed than treated food in each protocol (periodic: $F_{1.9}=26.9, \mathrm{p}<0.001$; continuous: $F_{1.9}=15.9, \mathrm{p}<0.001$ ). Separate analyses for each time period showed that in Tests 2 and 3, there was a significantly larger amount of control food consumed relative to treated food in the continuous protocol than in the periodic protocol (protocol $\times$ compound, Test 2: $F_{1,9}=7.3, p=0.025$; Test 3 : $\left.F_{1,9}=6.1, \mathrm{p}=0.035\right)$. Malyngamide $\mathrm{B}$ deterred feeding in both protocols, but the level of deterrence was greater in the continuous protocol than in the periodic protocol (Fig. 3c, d).

Malyngolide. Consumption of malyngolide did not show a significant compound $\times$ time $\times$ protocol interaction. However, for both protocols, significantly more control food was consumed than treated food (Table 3c, Fig. 3e, f). Parrotfish were therefore consistently deterred by malyngolide in each protocol.

\section{DISCUSSION}

While all 3 compounds from Lyngbya majuscula deterred feeding by juvenile rabbitfish and parrotfish, the magnitude of deterrence varied over time and between the 2 feeding protocols. Both rabbitfish and parrotfish were more deterred by malyngamides $A$ and $B$ when fed continuously than when fed only during preference tests. Fish fed less frequently (in the periodic protocol) may have been more hungry during

Table 3. Scarus schlegeli. Repeated measures ANOVAs of parrotfish consumption of foods treated with Lyngbya majuscula compounds. Only factors relevant to our hypotheses are shown

\begin{tabular}{|c|c|c|c|c|c|}
\hline Effect & df & Effect MS & Error MS & $F$ & $\mathrm{p}$ \\
\hline \multicolumn{6}{|l|}{ (A) Malyngamide A $0.5 \%$} \\
\hline Compound & 1,12 & 718627 & 17930 & 40.1 & $<0.001$ \\
\hline Compound $\times$ Time & 2,24 & 12432 & 3161 & 3.9 & 0.033 \\
\hline Compound $\times$ Protocol & 1,12 & 98402 & 13392 & 7.3 & 0.019 \\
\hline Compound $\times$ Time $\times$ Protocol & 2,24 & 18398 & 3160 & 5.8 & 0.009 \\
\hline \multicolumn{6}{|l|}{ (B) Malyngamide B $0.5 \%$} \\
\hline Compound & 1,9 & 147070 & 6174 & 23.8 & 0.001 \\
\hline Compound $\times$ Time & 2,18 & 688 & 1501 & 0.5 & 0.640 \\
\hline Compound $\times$ Protocol & 1,9 & 22331 & 3768 & 5.9 & 0.038 \\
\hline Compound $\times$ Time $\times$ Protocol & 2,18 & 1168 & 2227 & 0.5 & 0.601 \\
\hline \multicolumn{6}{|l|}{ (C) Malyngolide $0.4 \%$} \\
\hline Compound & 1,9 & 65812 & 2754 & 23.9 & $<0.001$ \\
\hline Compound $\times$ Time & 4,36 & 576 & 459 & 1.3 & 0.306 \\
\hline Compound $\times$ Protocol & 1,9 & 2768 & 783 & 3.5 & 0.093 \\
\hline Compound $\times$ Time $\times$ Protocol & 4,36 & 212 & 210 & 1.0 & 0.417 \\
\hline
\end{tabular}



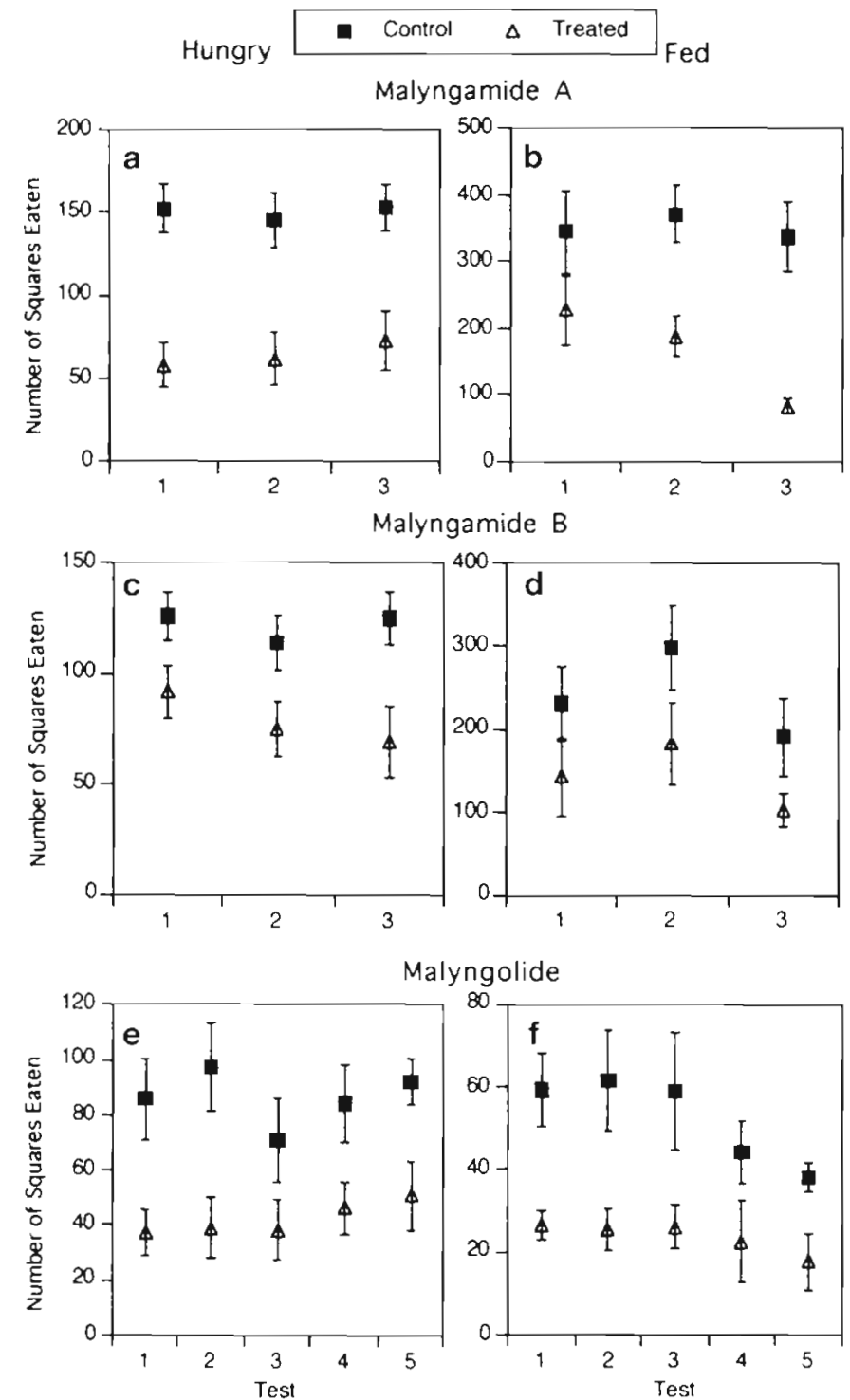

alyngolide

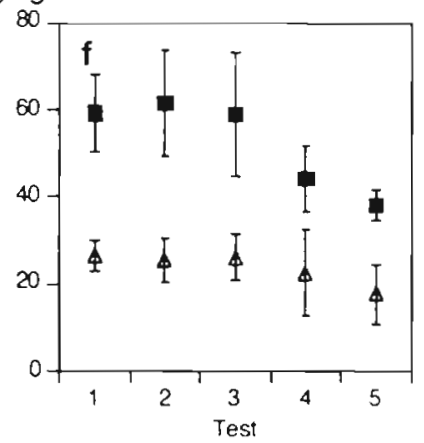

Fig. 3. Scarus schlegeli. Parrotfish consumption of control foods and foods treated with malyngamide $A$, malyngamide $B$, or malyngolide in periodic or continuous feeding protocols. Means and standard errors are plotted for each test. Note that the scales of the $y$-axes vary

the preference tests and had less exposure time to the experimental foods in 3 of the 6 series of tests. Most foraging animals are expected to be less selective when hungry (Schoener 1971, Hughes 1980, Stephens \& Krebs 1986), such that hungrier fish may less readily reject foods containing deterrent chemicals. Cronin \& Hay (1996) found that hunger stress caused sea urchins to be less responsive to defensive algal metabolites, with no reduction in feeding between control and treated foods for $2 \mathrm{~d}$ after a $3 \mathrm{~d}$ starvation period. DeMott (1993) reviews the effects of hunger on diet selection by suspension-feeding zooplankton. When zooplankton are more hungry, lower quality food particles (including those containing toxins) are consumed more readily.

In our experiments, fishes in 3 of the 6 continuous feeding protocols were allowed continuous access to control and treated foods (Table 1). In these protocols, fishes had more exposure time to the experimental foods than fishes in the periodic feeding protocols, and therefore had more opportunity to learn about the experimental foods. If more experience with an experimental food allows fishes to better discriminate between control and experimental foods, fishes with more experience may better learn to avoid the experimental food (Hughes 1979). In our assays, increases in deterrence were seen in 2 of the 3 feeding protocols with continuous access to control and experimental foods and in 1 of the 3 feeding protocols with continuous access to control foods.

All 3 compounds were deterrent in their initial tests, indicating the low palatability of these compounds to these fishes. An increase in deterrence over time could reflect a learned aversion to the treated food (Provenza et al. 1990). Fish could also become more sensitive to the treated foods over time (Goodenough et al. 1993). We found evidence of increased deterrence only in the continuous feeding protocols, not in the periodic feeding protocols. Rabbitfish showed an increased avoidance of malyngamides A and B in later tests, while parrotfish showed an increased avoidance of malyngamide $A$. The absence of an increased avoidance in parrotfish for malyngamide B may reflect differences in the physiological effects of this compound between fish species, i.e. that parrotfish are more tolerant of malyngamide $B$ than are rabbitfish. The lack of increased deterrence in. the periodic protocols indicates that either hunger stress or time exposed to foods can alter behavioral responses between preference tests, in addition to reducing selectivity within a test.

Although both species were consistently deterred by malyngolide, neither species reduced consumption of malyngolide over time. Additionally, even though the fishes learned to avoid malyngamides $A$ and $B$, these foods were sampled throughout the experiments. These results are similar to those of Provenza et al. (1990), who found that goats ingesting foods containing low and high concentrations of tannins continued to sample foods high in tannins, despite showing a learned aversion to these foods. Through this sampling, foragers can (1) reduce their likelihood of over-ingesting toxins, (2) change their intake of toxic foods as toxicity changes, and (3) find new foods (Provenza \& Cincotta 1993). For rabbitfish and parrot- 
fish, sampling could play an important role in finding patches of algae and benthic cyanobacteria that contain lower concentrations of defensive chemicals. Since the fishes in our experiments continued to sample, rather than completely ignore, the treated foods, the deterrent compounds we tested most likely do not have very strong post-ingestive effects. Fishes may learn to more completely avoid foods containing compounds that have more potent effects. For example, consumption of foods containing prostaglandins induces a vomiting response in some fishes, which then show nearly complete avoidance of these foods (Gerhart 1991).

Even though malyngolide was deterrent to both rabbitfish and parrotfish, the fishes showed no increased avoidance of malyngolide in either feeding protocol. On the contrary, for both rabbitfish and parrotfish, there was a trend toward a decrease in the deterrent effect of malyngolide. However, deterrence was maintained even in the final tests. Malyngolide may, therefore, be unpalatable, yet have no serious post-ingestive effects. Lee \& Bernays (1990) argue that an inverse relationship exists between the palatability of a food and how effectively animals can form an aversion to that food. If a food is unpalatable (even without any toxic post-ingestive effects), animals may also less readily learn to accept that food item. Fish may not have formed permanent aversions to these compounds because the fish limited their intake of the compounds. Hunger stress may make herbivores more susceptible to toxins and generate a lower consumption of toxintreated foods (Provenza 1996, Wang \& Provenza 1996).

In experiments with adult rabbitfish Siganus argenteus Paul et al. (1990) found that feeding was deterred by crude organic extracts of Lyngbya in an initial trial. However, in a second trial, this species of rabbitfish consumed equal amounts of control and treated foods. Adult $S$. argenteus may learn to accept extracts of $L y n$ gbya. Juvenile $S$ argenteus preferred to consume food treated with malyngamide $\mathrm{B}$ ( $1 \%$ dry weight) over control food (Paul et al. 1990). However, Paul et al. (1993) found that older $S$. spinus were deterred by crude organic extracts of Lyngbya. Our current experiments indicate that juvenile $S$. spinus are also deterred by compounds isolated from Lyngbya. Unlike juvenile $S$. argenteus, juvenile $S$. spinus do not show an enhancement of feeding by malyngamide $B$ or any other compounds. However, our experiments were limited to short time periods ( 3 to $5 \mathrm{~d}$ ), and over longer time periods, these fish may learn to accept or reject these foods more completely. Ontogenetic changes in rabbitfish food preferences have been documented (Bryan 1975). As these fish mature, they ingest a wider variety of algal species. Bryan (1975) suggested that these differences result from adults being better able to physically bite and ingest larger, tougher algal species. Physiological detoxification mechanisms may also improve as growth and development progress, thereby changing the susceptibility of rabbitfish to toxins in their diets.

Since we found evidence that either hunger or less exposure time to experimental foods may decrease feeding selectivity in these fishes, laboratory assays using fish to guide the isolation of chemical feeding deterrents should ensure that any test organisms are well-fed between assays and use consistent exposure times (Cronin \& Hay 1996). Preference tests of longer duration may be needed to show deterrence if fishes require more experience with experimental foods before they are able to discriminate between foods. In addition, the amount of sampling at the initial tests of each of our trials indicates that learning did not generalize between compounds or feeding protocols. Feeding fish control food for $3 \mathrm{~d}$ between trials was sufficient to minimize any effects of learning between trials.

Our results indicate that these coral reef fishes can learn to avoid defensive secondary metabolites, but that this learning does not occur when access to food is limited. Since increases in hunger can decrease the deterrent effects of anti-feedant compounds, fish may consume broader diets when more palatable algae are less abundant. This behavioral mechanism may explain the field observations that juvenile rabbitfish seem to consume the most palatable algae on a reef first, and then gradually begin to consume less palatable algae as the abundance of palatable algae decreases. This strategy may indicate that the effectiveness of the chemical defenses of an alga or cyanobacteria is dependent on the state of the consumer and the defenses of other prey in the environment.

Acknowledgements. This work was supported by NSF grant HRD-9023311 awarded to V.J.P. We thank W. Yoshida (Dept of Chemistry, Univ. of Hawaiij for NMR assistance, R. K. Sakamoto and F. Cushing for collecting fish, G. W. Fowler (Univ. of Michigan) for statistical advice, and 3 anonymous reviewers for their comments on the manuscript. This is contribution no. 381 from the University of Guam Marine Laboratory.

\section{LITERATURE CITED}

Bryan PG (1975) Food habits, functional digestive morphology, and assimilation efficiency of the rabbitfish Siganus spinus (Pisces, Siganidae) on Guam. Pac Scl 29(3):269-277

Cronin G, Hay ME (1996) Susceptibility to herbivores depends on recent history of both the plant and animal. Ecology 77:1531-1543

DeMott WR (1993) Hunger-dependent diet selection in suspension-feeding zooplankton. Hughes RN (ed) Diet selection. Blackwell Sci Publ, London, p 102-123 
Dill LM (1983) Adaptive flexibility in the foraging behavior of fishes. Can J Fish Aquat Sci 40:398-408

Gerhart DJ (1991) Emesis, learned aversion, and chemical defense in octocorals: a central role for prostaglandins? Am J Physiol 260:R839-R843

Goodenough J, McGuire B, Wallace RA (1993) Perspectives on animal behavior. John Wiley \& Sons, New York

Hay ME, Kappel QE, Fenical W (1994) Synergisms in plant defenses against herbivores: interactions of chemistry, calcification, and plant quality. Ecology 75(6):1714-1726

Hughes RN (1979) Optimal diets under the energy maximization premise: the effects of recognition time and learning Am Nat 113:209-221

Hughes RN (1980) Optimal foraging theory in the marine context. Oceanogr Mar Biol Annu Rev 18:423-481

Kami HT, Ikehara II (1976) Notes on the annual juvenile Siganid harvest in Guam. Micronesica 12(2):323-325

Lee JC, Bernays EA (1988) Declining acceptability of a food plant for the polyphagous grasshopper Schistocerca americana: the role of food aversion learning. Physiol Entomol 13:291-301

Lee JC, Bernays EA (1990) Food tastes and toxic effects: associative learning by the polyphagous grasshopper Schistocerca americana (Drury) (Orthoptera: Acrididae). Anim Behav 39:163-173

Lumbang WA, Paul VJ (1996) Chemical defenses of the tropical green seaweed Neomeris annulata Dickie: effects of multiple compounds on feeding by herbivores. J Exp Mar Biol Ecol 201:185-195

Mitchell WA (1990) An optimal control theory of diet selection: the effects of resource depletion and exploitative competition. Oikos 58:16-24

Moore RE (1981) Constituents of blue-green algae. In: Scheuer PJ (ed) Marine natural products, Vol 4. Academic Press, New York

Paul VJ, Meyer KD, Nelson SG, Sanger HR (1993) Deterrent effects of seaweed extracts and secondary metabolites on feeding by the rabbitfish Siganus spinus. Proc 7 Int Coral Reef Symp, Guam, Vol 2, p 867-874

Paul VJ, Nelson SG, Sanger HR (1990) Feeding preferences of

This article was presented by C. Birkeland, Guam, USA adult and juvenile rabbitfish Siganus argenteus in relation to chemical defenses of tropical seaweeds. Mar Ecol Prog Ser 60:23-34

Paul VJ, Pennings SC (1991) Diet-derived chemical defenses in the sea hare Stylocheilus longicauda (Quoy et Gaimard 1824). J Exp Mar Biol Ecol 151:227-243

Pennings SC, Paul VJ (1993) Secondary chemistry does not limit dietary range of the specialist sea hare Stylocheilus longicauda (Quoy et Gaimard 1824). J Exp Mar Biol Ecol 174:97-113

Pennings SC, Weiss AM, Paul VJ (1996) Secondary metabolites of the cyanobacterium Microcoleus lyngbyaceus and the sea hare Stylocheilus longicauda: palatability and toxicity. Mar Biol 126:735--743

Provenza FD (1996) Acquired aversions as the basis for varied diets of ruminants foraging on rangelands. J Anim Sci 74 : $2010-2020$

Provenza FD, Burritt EA, Clausen TP, Bryant JP, Reichardt PB, Distel RA (1990) Conditioned flavor aversion: a mechanism for goats to avoid condensed tannins in blackbrush. Am Nat 136(6):810-828

Provenza FD, Cincotta RP (1993) Foraging as a self-organizational learning process: accepting adaptability at the expense of predictability. In: Hughes RN (ed) Diet selection. Blackwell Sci Publ, London, p 78-101

Rozin P (1976) The selection of foods by rats, humans, and other animals. Adv Study Behav 6:21-76

Schoener TW (1971) Theory of feeding strategies. Annu Rev Ecol Syst 2:369-403

Stephens DW, Krebs JR (1986) Foraging theory. Princeton University Press, Princeton

Tsuda RT, Bryan PG (1973) Food preference of juvenile Siganus rostratus and S. spinus in Guam. Copeia 1973:604-606

Wang J, Provenza FD (1996) Food deprivation affects preference of sheep for foods varying in nutrients and a toxin. J Chem Ecol 22:2011-2022

Wilkinson L, Hill M, Vang E (1992) SYSTAT Statistics, version 5.2. Systat, Evanston, IL

Winer BV (1971) Statistical principles in experimental design. McGraw-Hill, New York

Manuscript first received: July 1, 1996

Revised version accepted: December 12, 1996 